\title{
Experimental Investigation on the Behavior of AlSiMgMn Alloy Inoculated by Al-5Ti Master Alloy and Fabricated by Die-Casting with Different Mold Wall Thicknesses
}

\author{
Kh. Abd El-Aziz ${ }^{\mathrm{a}, \mathrm{b}, *}$ and Ageel Alogla ${ }^{\mathrm{a}}$ \\ ${ }^{a}$ Mechanical Engineering Department, Faculty of Engineering, Taif University, Saudi Arabia. \\ ${ }^{b}$ Materials Engineering Department, Faculty of Engineering, Zagazig University, P.O. Box 44519, Egypt. \\ *Corresponding author:(Kh. Abd El-Aziz).
}

ORCID: 0000-0001-9139-548X (Kh. Abd El-Aziz)

\begin{abstract}
Aluminum-base alloys are widely utilized in many engineering industries such as automotive, structural applications, shipbuilding and transportation industries due to their high strength to weight ratio and corrosion resistance. AlSiMgMn alloy is one of the most widely used alloys and has considerable industrial attention. In the current study, the effect of the addition of Al-5Ti master alloy with different percentages on the microstructure and mechanical properties of AlSiMgMn alloy were investigated. The investigated alloys with AL-5Ti master alloy were fabricated using die casting method. The mold wall thickness was considered as a one of the important casting parameters in metal casting, which affects the rate of solidification. The effect of steel mold wall thickness during solidification of the molten metal on the microstructure and mechanical properties was also investigated. The present results showed that, the addition of AL-5Ti master alloy (from 0 to 2 wt.\%) to AlSiMgMn alloy resulted in fine-grained structure and better mechanical properties. In addition, with the increasing of Al-5Ti addition from $0 \%$ to $2 \%$ wt. $\%$, the UTS improved from 165 to $208 \mathrm{MPa}$ and the yield strength was increased from 125 to $160 \mathrm{MPa}$ respectively, while the addition of 3\%wt. of Al-5Ti master alloy did not reveal any marked improvements in these properties. During solidification of the molten alloy metal, the rate of cooling increases as the mold wall thickness increases, therefore the as-cast dendritic grains become smaller. The microstructure of the casting near the mold wall reveals fine-grains structure, while it shows coarse grains at the inner surface of the casting. This will result in a higher microhardness near the mold wall and lower at the inner of the casting as indicated in the current study.
\end{abstract}

Keywords; Al-Si-Mg-Mn alloy; Microstructure; Al-5Ti master alloy; Mechanical properties; Microhardness; Grain size; Mold wall thickness.

\section{INTRODUCTION}

Aluminum alloys offer an enormously wide range of competency and applicability, with exceptional combination of advantages that makes them appropriate material for several mechanical and engineering applications. Aluminummagnesium-silicon-manganese (AlMgSiMn) designated as
6XXX series Al-base nonferrous alloys are recognized as casting alloys with good weldability, mechanical properties and corrosion resistance characteristics [1-4]. They have been extensively used in structural applications, automobile, aerospace and many other engineering industries because of their excellent weldability, formability, corrosion resistance and other desirable mechanical properties [4-6]. It is well known that the grain refiner (GR) plays an important role in enhancing the mechanical properties and characteristics of the as-cast and wrought aluminum-base alloys. Typically, the master alloys like Al-Ti and Al-Ti-B are used with aluminum alloys during the process of grain refinement [7]. Grain refinement can be assumed to be directly related to the nucleation and growth processes of aluminum alloy grains during solidifications. It is considered to be an important treatment process of the melt that occurs during the casting of aluminum alloys. The grain refinement was accomplished by heterogeneous nucleation through the use of inoculants methods by using commercial master alloys [1]. When the grain refiner added to molten metal, it takes some time for nucleation process. The time required to reach the desired grain size is denoted as optimal contact time. The introducing of inoculate particles into the molten metal is the most effective method to achieve small uniformly distributed equiaxed grains, which leads to high toughness, high yield strength, good formability and better machinability [2,8,9]. Wang et al. [10] recommended that the $\mathrm{Ti}, \mathrm{V}, \mathrm{Zr}$ and $\mathrm{Nb}$ elements prompted constitutional supercooling and provided heterogeneous nucleation sites in the melt $[10,11]$. Titanium is considered as the most effective grain refining element, due to the formation of $\mathrm{TiAl}_{3}$ that act as a heterogeneous inoculants $[12,13]$. When used alone, the effect of $\mathrm{Ti}$ diminishes with the increasing of the time of holding in the molten state and repeated melting of the cast metal. Zhang et al. [14] decided that adding small amount of $\mathrm{Ti}$ to the alloy Al-Mg-Zn-Si lead to formation of $\mathrm{Al}_{3} \mathrm{Ti}$ phase, and improved the mechanical properties of this alloy significantly. Nevertheless, the Ti content should be controlled below $0.10 \%$, because of the excess of titanium will form coarse $\mathrm{Al}_{3} \mathrm{Ti}$ particles, which may reduce the mechanical properties of the investigated alloy. Ding et al. [15] studied grain-refining performance of three types of $\mathrm{Al}-5 \mathrm{Ti}$ master alloys with different microstructures in grain refinement of commercial aluminum. They concluded that, Al-5Ti with TiAl3 blocky-shape particles obviously has well refining 
efficiency than the Al-5Ti with mixed-like $\mathrm{TiAl}_{3}$ particles and with TiAl3 needle-like particles when containing same content of master alloy. The microstructures of all $\mathrm{Al}-5 \mathrm{Ti}$ master alloys with different sizes, morphologies and amounts of intermetallic $\mathrm{TiAl}_{3}$ crystals, were observed to affect the configuration of the grain refining characteristics with the suitable holding time [15]. The effect of grain refinement was shown to decline distinctly for TiAl3 needle-like particles and to display more significant enhancement at a longer time for both $\mathrm{TiAl} 3$ particles. The permanent mold casting process including highpressure die casting is presently the most common process for manufacturing components by metal casting [16]. The solidification time and quality of the final casting are dependent upon various parameters such as mold wall thickness, pouring temperature, mold material, shape and size of the mold and time of pouring into the mold $[17,18]$. The rate at which a casting solidifies during casting process will affects its final structure and mechanical properties [19]. Bala et al. [20] studied the rate of solidification of aluminum casting in varying wall thickness of cylindrical metallic molds. They reported that, solidification time is lower for cylindrical mold with bigger mold thickness due to the chilling effect of the mold. Madhusudhan et al. [19] and Abd El-Aziz et al. [21] and concluded that, solidification rate increases as the mold wall thickness increases. Therefore, the rate of cooling also increases, hence the grains of the cast become finer. In this study, the effect of the addition of different percentages of Al-5Ti master alloy on the microstructure and mechanical properties of AlSiMgMn alloy was investigated. The influence of mold wall thickness during casting process on the microstructure and mechanical properties was also investigated.

\section{EXPERIMENTAL WORK}

In this work, the alloy AlSiMgMn with different fractions of Al-5Ti master alloy as grain refiner were fabricated by permanent mold casting method. The AlSiMgMn alloy, which used as a base metal in the present study, contains $1.2 \% \mathrm{Si}$, $0.93 \% \mathrm{Mg}, 0.7 \% \mathrm{Mn}$ and $0.4 \% \mathrm{Fe}$. At first, the AlSiMgMn alloy was melted in crucible furnace at $725^{\circ} \mathrm{C}$. Afterwards, the $\mathrm{Al}-$ 5Ti master alloy with different amounts of $0,1,2$ and 3.\% was introduced into the melt to produce the required casting. The melt was poured into metallic steel molds with different wall thicknesses of 8,18 and $28 \mathrm{~mm}$ to impose the cooling rate. After carrying out the fabrication process, the as-cast alloys are prepared for proceeding microstructural and mechanical tests. After solidification, the cast aluminum alloys were cut using cut-off machine and machined to prepare the required tensile test specimens according to ASTM: E8/E8M-16 standard as shown in Fig. 1. The tensile tests are performed on short round test specimens with a diameter of $12.5 \mathrm{~mm}$ and gage length of $62.5 \mathrm{~mm}$ using a $300 \mathrm{kN}$ capacity universal testing machine. Standard metallographic techniques were required to study the microstructures of the different specimens. Metallographic specimens are ground and polished using $\mathrm{SiC}$ abrasive emery papers, ranged from 180 to 1200 grit size and etched by a reagent contains $75 \mathrm{ml} \mathrm{HCl}, 25 \mathrm{ml} \mathrm{HNO} 3,5 \mathrm{ml} \mathrm{HF}$, and $25 \mathrm{ml}$ $\mathrm{H} 2 \mathrm{O}$ to reveal their microstructure constituents. The microstructures at the different positions on the specimen surface were characterized using an optical microscope, a scanning electron microscope (SEM) equipped with energy dispersive X-ray spectrometer (EDS). The average grain size is measured according to E112ASTM standard. Microhardness is measured after grinding and polishing processes of the tested specimens using a VHS-1000 microhardness testing machine at load of $50 \mathrm{~g}$.
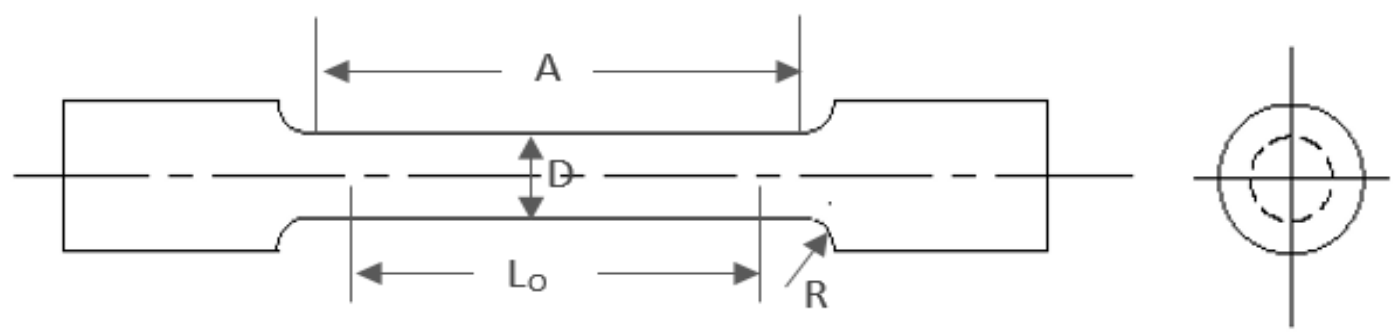

$$
\begin{aligned}
& \text { Lo }=62.5 \mathrm{~mm} \\
& A=75 \mathrm{~mm} \\
& D=12.5 \mathrm{~mm} \\
& R=5 \mathrm{~mm}
\end{aligned}
$$

Fig. 1: Standard tensile test specimen according to ASTM-E16

\section{RESULTS AND DISCUSSION}

\section{III.I. Microstructure characteristics}

The results of SEM/EDS analysis for the AlSiMgMn alloy and Al-5Ti master alloy are presented in Fig. 2. Fig. 2-a shows SEM micrograph of AlSiMgMn alloy. From the Figure, it is clear that microstructure of the alloy AlSiMgMn consists of $\alpha-\mathrm{Al}$ dendrites and inter-dendritic regions of eutectic phase. The spectrum and mass fractions (EDS) of the elements at different regions in the microstructure of AlSiMgMn alloy, which shown in Fig. 2-c, reflect the phases present in the microstructure as is mentioned. SEM/EDS analysis for the Al-5Ti master alloy are shown in Figs. 2-b and 2-d. As shown in this figures, SEM/EDS reflects the presence of intermetallic TiAl3 particles in the microstructure of the Al-5Ti master alloy. Fig. 3 shows the Xray diffraction (XRD) plot of Al-5Ti master alloy used in the present study as a grain refiner. Fig.4 shows the optical micrographs of the as-cast microstructure of AlSiMgMn alloy with $0,1,2,3 \%$ of Al-5Ti master alloy. It is obvious from this figure that addition of $\mathrm{Al}-5 \mathrm{Ti}$ master alloy as grain refiner resulted in grain refinement of AlSiMgMn alloy. In Fig. 4-a, it is clear that the microstructure of AlSiMgMn alloy consists of coarse $\alpha-\mathrm{Al}$ dendritic and inter-connected microstructure. The addition of Al-5Ti to AlSiMgMn alloy led to variations in the morphology of the $\alpha$-Al phase from coarse dendrites to relatively fine equiaxed microstructure as shown in Figs. 4- 
(b,c,d). It is clear also that the size of grains decreases with the increasing of the amount of Al-5Ti master alloy, and smaller grain size was absorved for the AlSiMgMn alloy with $2 \% \mathrm{Al}-$ 5Ti. This confirms the uniform distribution of insoluble substrates in the Al-matrix, which acts as nucleation sites for primary $\alpha-\mathrm{Al}$ phase.

\section{III.II. Mechanical properties of the AISiMgMn Alloy with different wt.\% of AL-5Ti}

According to the tensile test results, the addition of grain refiner Al-5Ti improves the mechanical properties of AlSiMgMn alloy as compared base alloy without GR. Fig. 5 and Fig. 6 illustrates the mechanical properties of the AlSiMgMn alloy having different amounts of grain refiner Al-5Ti alloy. From Fig. 5, it is noticed that the ultimate tensile strength (UTS) and yield strength of the AlSiMgMn alloys was enhanced with the addition of Al-5Ti master alloy. The UTS and yield strength increased from $175 \mathrm{MPa}$ and $125 \mathrm{MPa}$ to $219 \mathrm{MPa}$ and 160
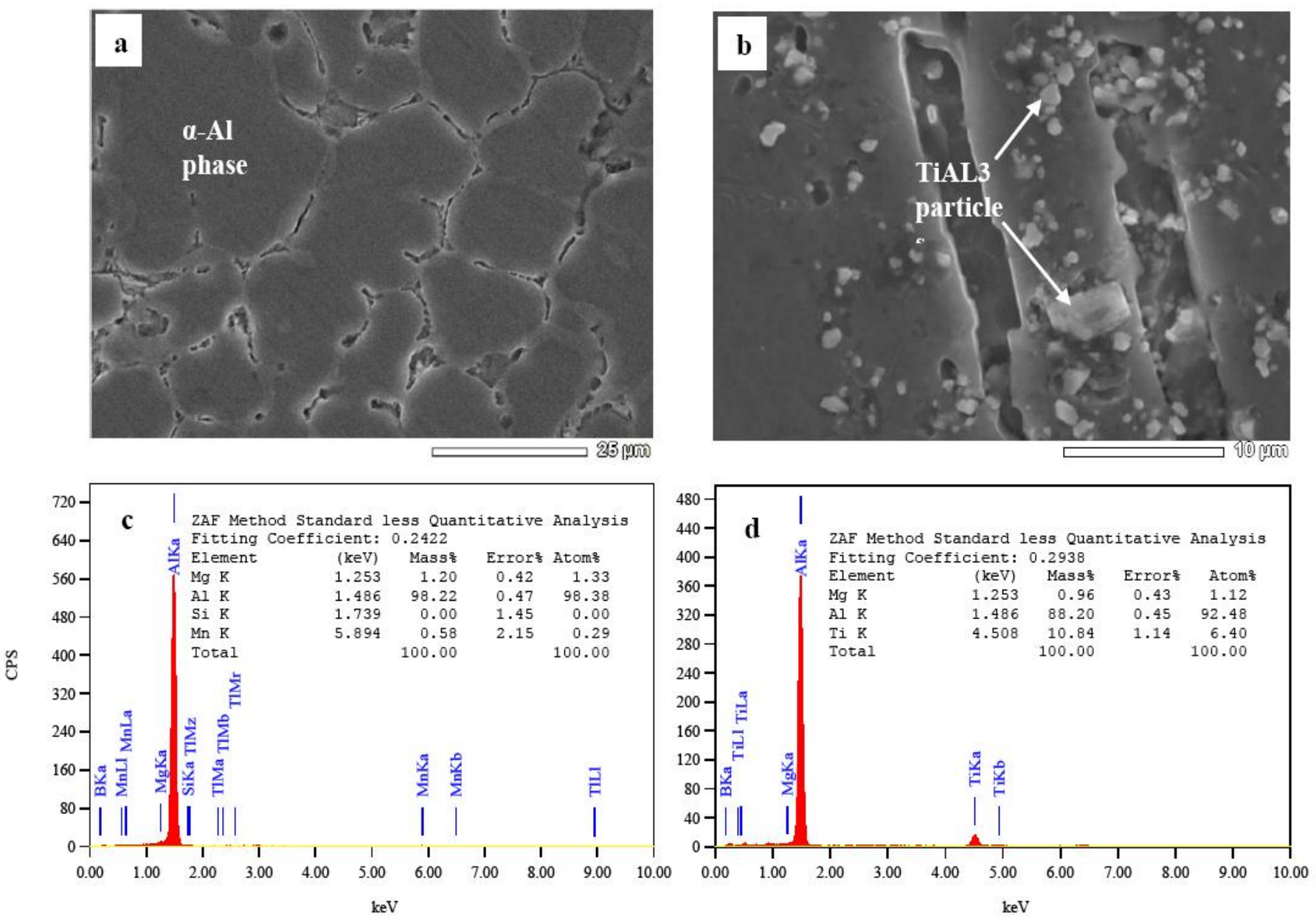

Fig. 2: (a), (c) SEM/EDS analysis for the AlSiMgMn alloy; (b), (d) SEM/EDS analysis for the Al-5Ti master alloy, respectively.
$\mathrm{MPa}$, respectively with the increasing of Al-5Ti master alloy up to $2 \%$. The best mechanical properties were observed for the alloy with $2 \%$ Al-5Ti master alloy. When the Al-5Ti master alloy content exceeds 2 wt. $\%$, the mechanical properties decrease. Fig. 6 shows the elongation percentage at failure of the AlSiMgMn alloy with different wt.\% of Al-5Ti master alloy. As shown in the figure, the elongation percentage values of the AlSiMgMn alloy increased from $8 \%$ to $11.4 \%$ with addition of 2\% Al-5Ti master alloy. From the microstructural observation, it is obvious that the addition of $\mathrm{Al}-5 \mathrm{Ti}$ master alloy to AlSiMgMn alloy resulted in formation of smaller grain size and enhancement in the structure morphology from coarsedendritic structure to relatively fine-equiaxed grains as shown in Fig. 7. Fig. 7 displays the SEM micrographs which shows the microstructures of AlSiMgMn alloy having different percentages of Al-5Ti.The reduction in the average grain size led to improvement in tensile properties of AlSiMgMn alloy as indicated above. The XRD diffraction plots confirmed the presence of TiAl3 phase, which acts as heterogeneous nucleant for primary $\alpha$-phase nucleation.

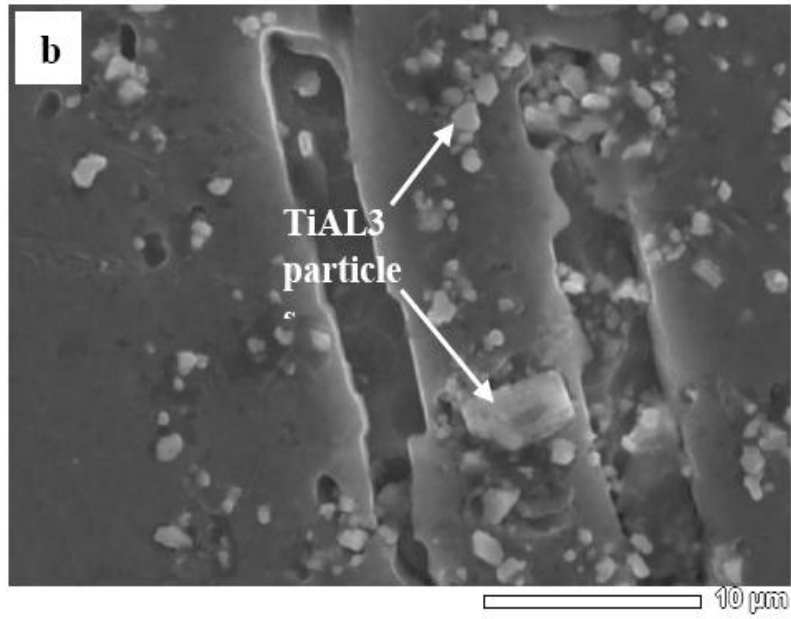


International Journal of Engineering Research and Technology. ISSN 0974-3154, Volume 13, Number 7 (2020), pp. 1764-1774

(C) International Research Publication House. https://dx.doi.org/10.37624/IJERT/13.7.2020.1764-1774

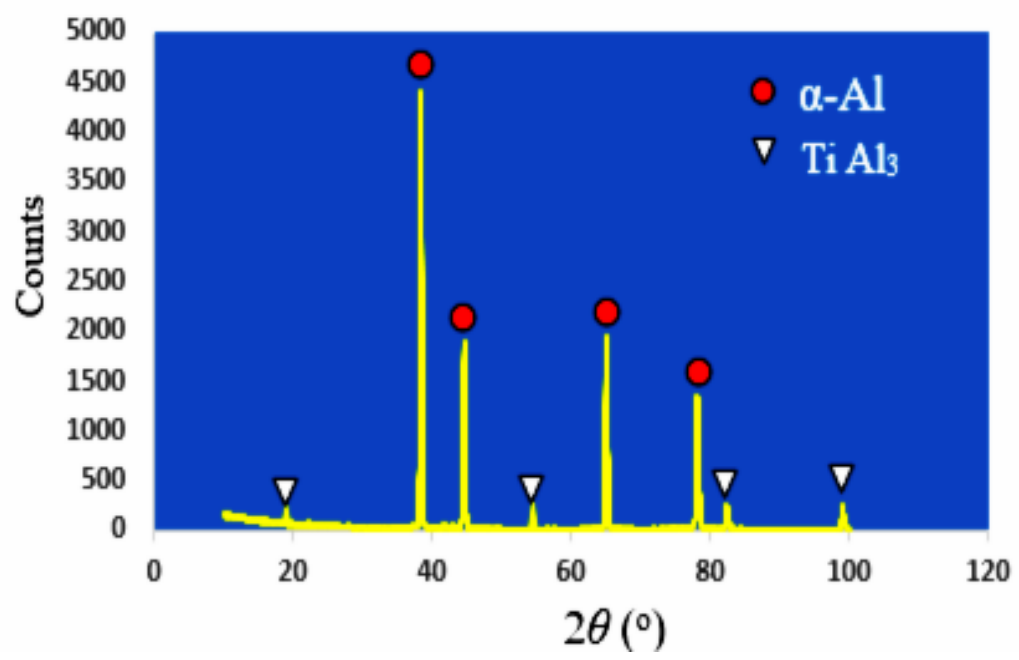

Fig. 3: XRD traces for Al-5Ti master alloy used in the present study.
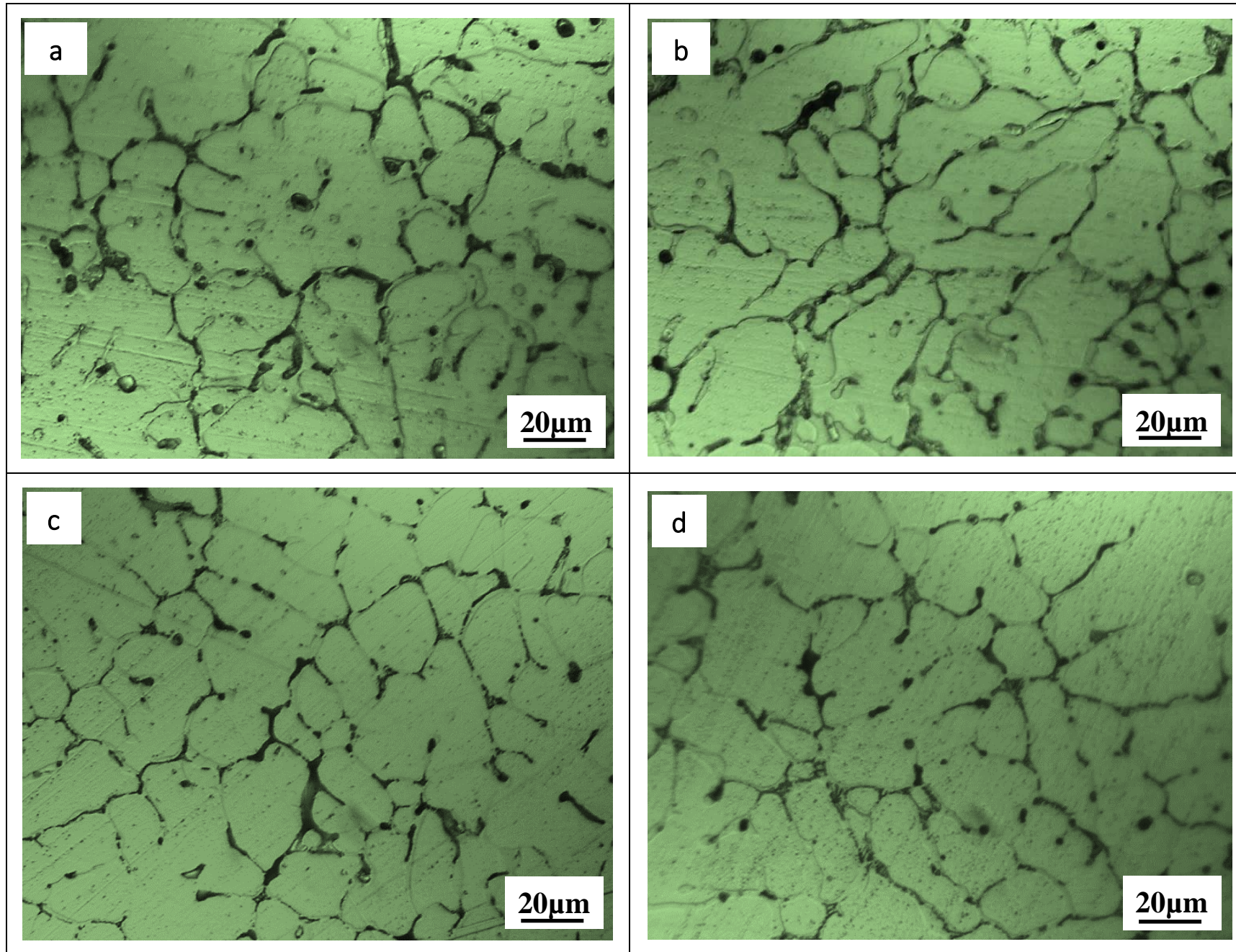

Fig.4: Optical micrographs show the microstructure of AlSiMgMn alloy with $0,1,2,3 \%$ Al-5Ti at higher magnifications x500; (a) 0\% Al-5Ti, (b) 1\% Al-5Ti, (c) 2\% Al-5Ti, and (d) 3\% Al-5Ti. 
International Journal of Engineering Research and Technology. ISSN 0974-3154, Volume 13, Number 7 (2020), pp. 1764-1774

(C) International Research Publication House. https://dx.doi.org/10.37624/IJERT/13.7.2020.1764-1774

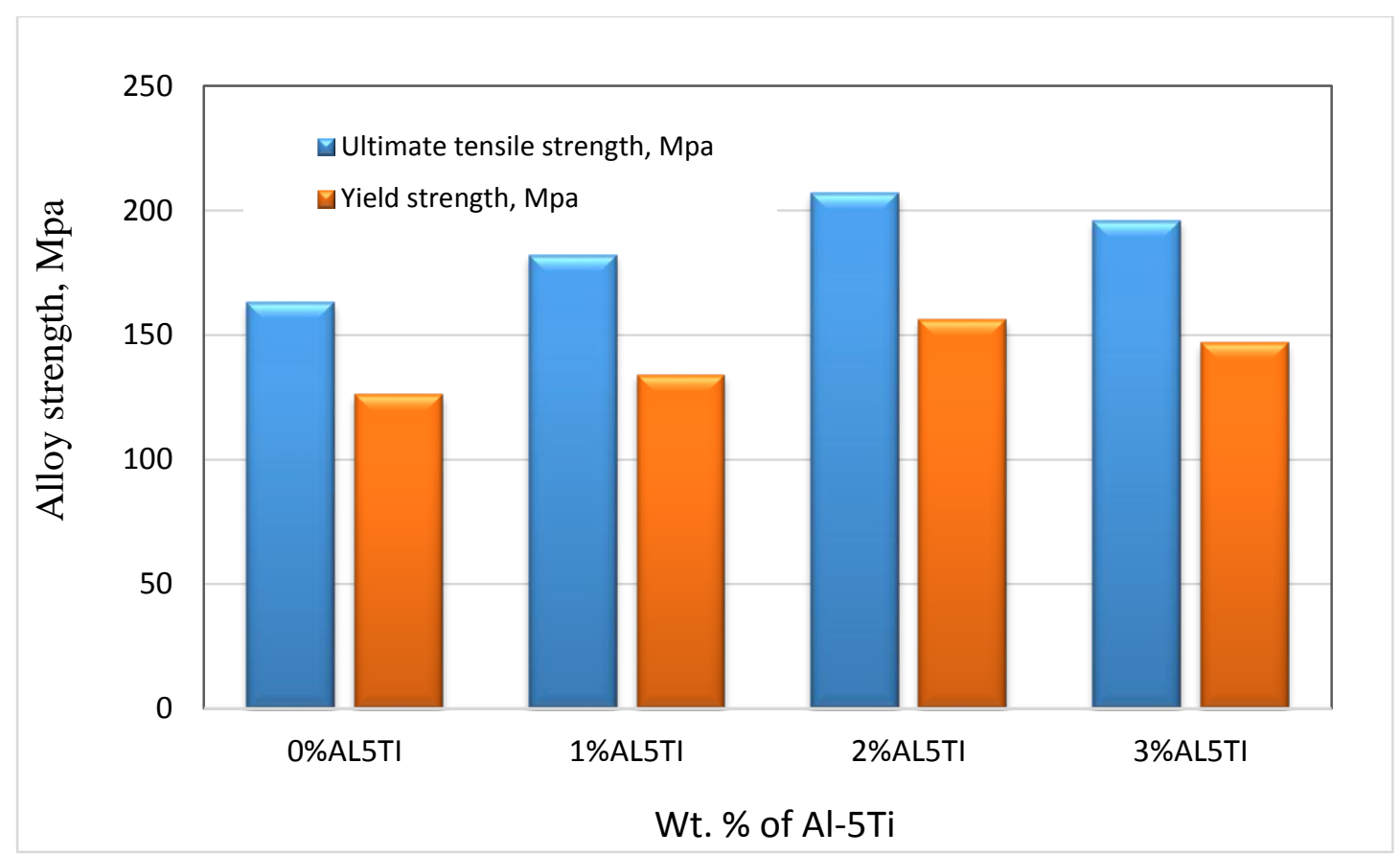

Fig. 5: Mechanical properties of the AlSiMgMn alloy with different wt.\% of Al-5Ti master alloy in as-cast condition.

Cibula A. [22] noticed that the use of $\mathrm{Al}-5 \mathrm{Ti}$ as grain refiner, introduces titanium in to the alloy melt in the form of TiAl3. He suggested that TiAl3 particles act as insoluble substrates for primary $\alpha$-phase nucleation. Fig. 8: shows the effect of addition of Al-5Ti master alloy on average grain size of AlSiMgMn alloy. From the figure, it is clear that average grain size decreased from $82 \mu \mathrm{m}$ in $\mathrm{AlSiMgMn}$ alloy without addition of Al-5Ti to $55 \mu \mathrm{m}$ in grain-refined alloy with addition of $2 \% \mathrm{Al}-$ 5Ti. The mechanism of grain refinement of AlSiMgMn alloy by the addition of Al-5Ti master alloy can be attributed to the formation of $\mathrm{TiAl} 3$ phase, which offers more nucleation sites for heterogeneous nucleation [23,24,25].The hardness values of the AlSiMgMn alloy with the additions of different wt.\% of Al5Ti master alloy are shown in Fig. 9. The increase in the hardness of AlSiMgMn alloy with the addition of $\mathrm{Al}-5 \mathrm{Ti}$ master alloy is chiefly attributed to the change in morphology of primary $\alpha-\mathrm{Al}$ grain from coarse dendritic structure to fine equiaxed structure.

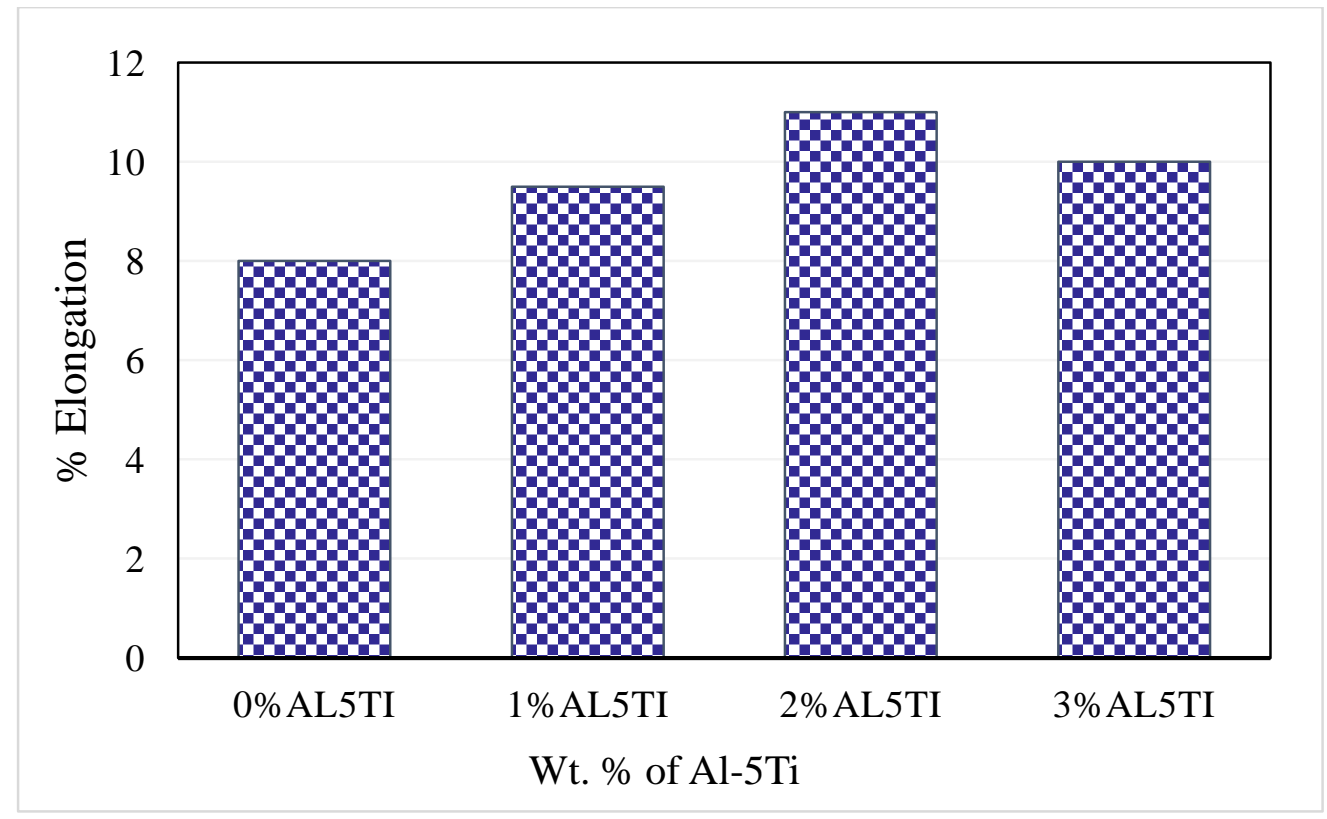

Fig. 6: Percentage elongation at failure of the AlSiMgMn alloy with different wt.\% of Al-5Ti master alloy in as-cast condition. 




Fig. 7: SEM shows the microstructure of AlSiMgMn alloy with; (a) 0\% Al-5Ti, (b) 1\% Al-5Ti, (c) $2 \% \mathrm{Al}-5 \mathrm{Ti}$, and (d) $3 \% \mathrm{Al}-5 \mathrm{~T}$.

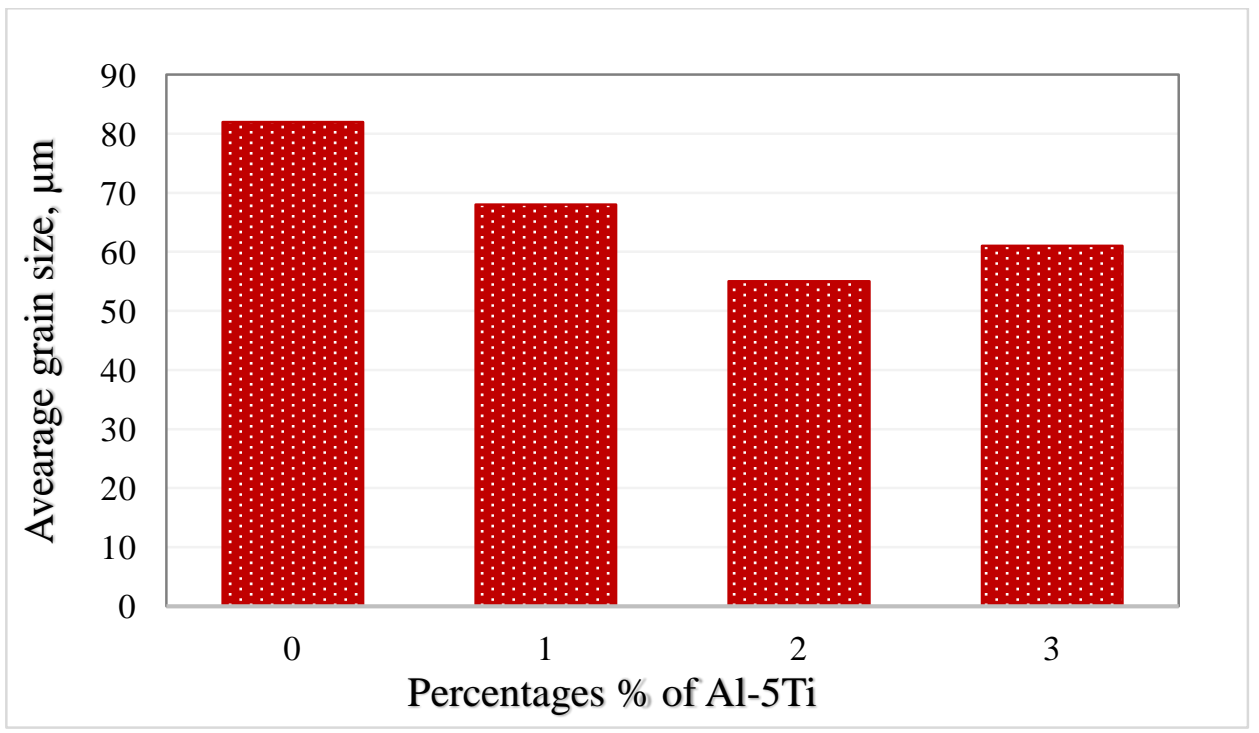

Fig. 8: Average grain size for the AlSiMgMn alloy with different wt.\% of Al-5Ti master alloy and mold wall thickness of $28 \mathrm{~mm}$. 


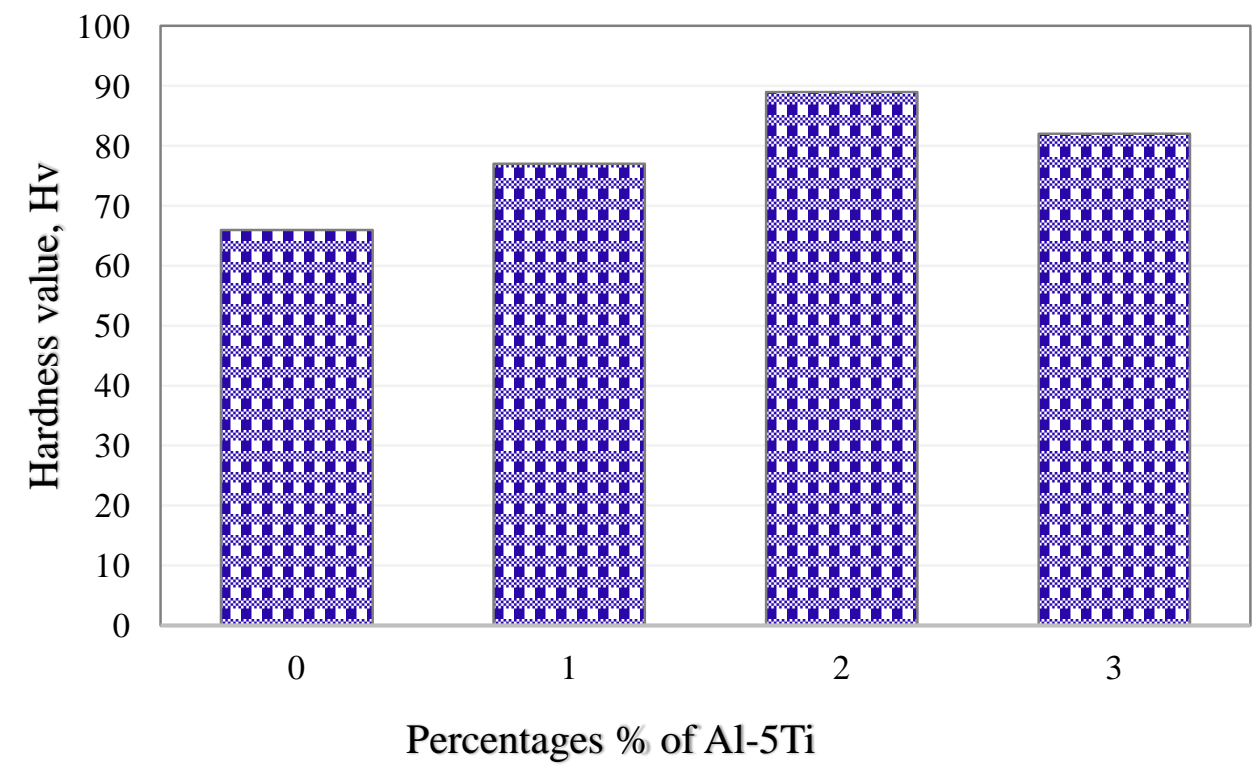

Fig. 9: Hardness for the AlSiMgMn alloy with different wt.\% of Al-5Ti master alloy and mold wall thickness of $28 \mathrm{~mm}$.

\section{III.III. Effect of mold wall thickness on the microstructure and properties of AlSiMgMn Alloy}

Fig. 10 shows the microstructure of AlSiMgMn alloy with different mold wall thickness at distance of $3,9 \mathrm{~mm}$ from the cast surface. From Fig.10, it is evident that the inter-dendritic and $\alpha$-Al dendrites become finer with increasing cooling rate. Three steel molds with different wall thicknesses of $8 \mathrm{~mm}$, $18 \mathrm{~mm}$ and $28 \mathrm{~mm}$, will be considered in this study. The different mold thicknesses were designed to attain different solidification rates during casting process. It was observed that the mold wall thickness influenced the microstructure of the AlSiMgMn cast alloy markedly. The microstructures of the alloy became finer with faster solidification rate and with the increasing of wall thickness as shown in these Figs. 10 (a-f). This is may be due to the increasing of mold wall thickness increases the cooling rate. This is in a good agreement with the previous studies [26,27]. In this figures, it is also clear that the size of $\alpha$-Al dendrites and inter-dendritic regions differs according to the distance from the cast surface. Where the microstructure region very close to the mold wall solidified faster and the microstructure region which is away from the mold wall cools slightly slower [28]. Such performance is consider that the grain refinement could be influenced by the cooling conditions. Rapid solidification rates display the welldistributed fine-grains and slow solidification rate reveals coarse-grain size [26].

Fig. 11 shows the effect of the mold wall thickness on the average grain size of the microstructure of the AlSiMgMn alloy. As shown in this figure, when the mold wall thickness increased from 8 to $28 \mathrm{~mm}$, the average grain size of the alloy decreased from 69 to $56 \mu \mathrm{m}$, respectively, at the distance $3 \mathrm{~mm}$ from specimen surface. The average grain size of the alloy also decreased from 86 to $76 \mu \mathrm{m}$ at the distance $9 \mathrm{~mm}$ from specimen surface. The reason why the mold wall thickness had clear effects on the microstructure and average grain size is the speed of solidification, which would significantly affect the grain refinement [29]. Kang et al. [30] concluded that the higher cooling rate offers a bigger undercooling, which renders the critical radius of nucleus smaller. This means it is easier to form more nuclei in the melt. On the other hand, there is no sufficient time for grains to grow into coarse phase forms. Both of these two aspects are attributed to the resultant finer microstructure at a higher cooling rate. Fig. 12 indicates the microhardness values for the castings with different mold wall thicknesses. From this figure, it is obvious that the microhardness values increases with increasing of mold wall thickness as a consequence of high cooling rates at the casting surface near to the wall of the mold. It is also clear that the microhardness of the AlSiMgMn alloy with $28 \mathrm{~mm}$ mold wall thickness (near to the wall of the mold) was $82 \mathrm{HV}$, and decreased to $68 \mathrm{HV}$ with mold wall thickness of $8 \mathrm{~mm}$ at a distance of $3 \mathrm{~mm}$ from internal mold wall as shown in Fig.12. Each value is an average of five values. The microhardness of the casting with $18 \mathrm{~mm}$ wall thickness was $78 \mathrm{HV}$ at a distance of $3 \mathrm{~mm}$ from internal mold wall and $67 \mathrm{HV}$ near to the specimen center. The decrease in the microhardness with the decreasing of mold wall thickness may be attributed to the increasing in average grain size as shown in Fig.10. Where the microstructures with minimum mold thickness reveals larger grain size due to slow cooling rates and casting obtained from bigger mold wall thickness displays fine grains, this is due to rapid cooling of the casting. 

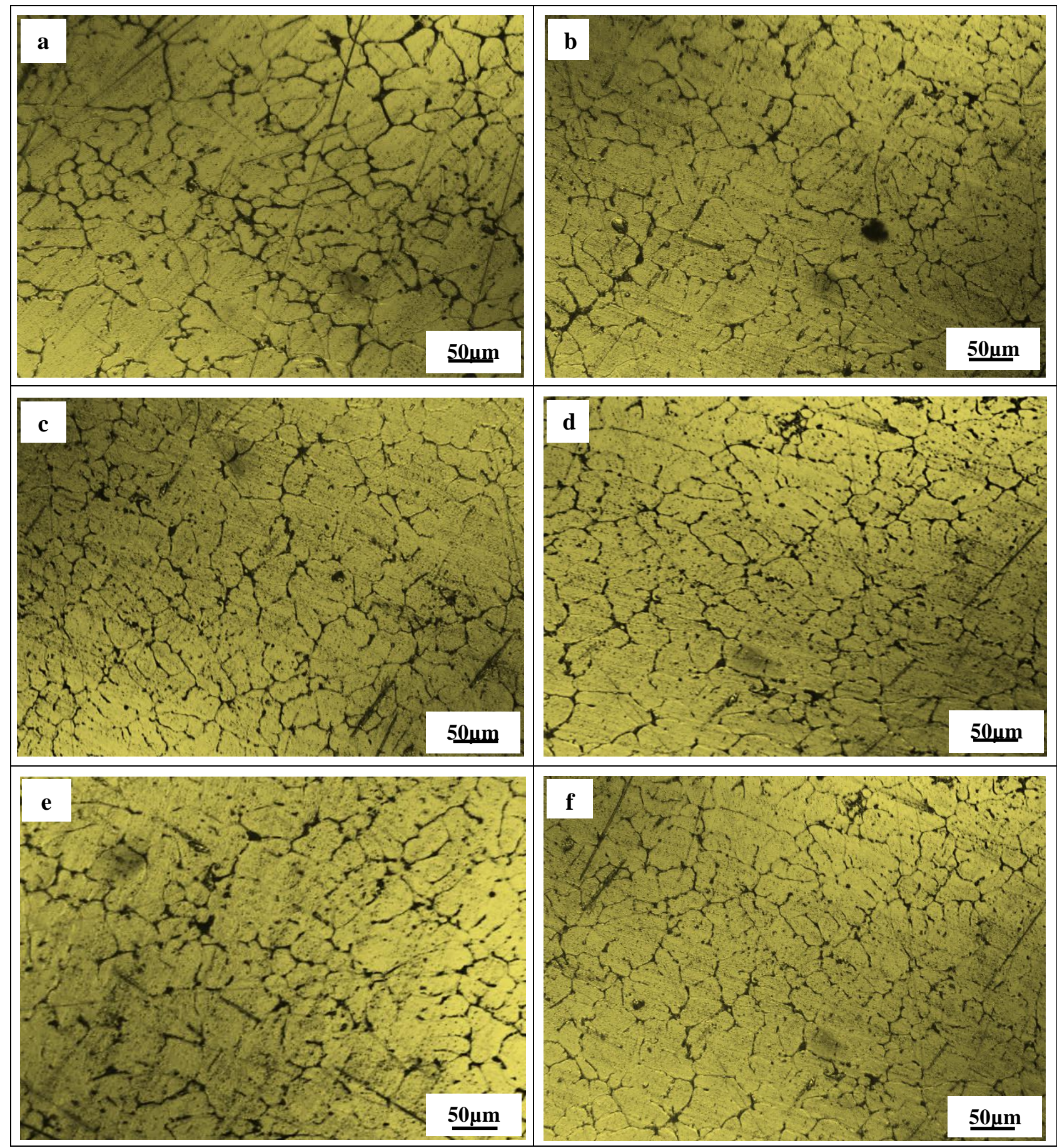

Fig. 10: Optical microstructure of the AlSiMgMn alloy with $0 \%$ Al-5Ti after casting in steel molds with different thicknesses at distances $9,3 \mathrm{~mm}$ from specimen surface; (a), (b) with $\mathrm{t}=8 \mathrm{~mm}$; (c), (d) with $\mathrm{t}=18 \mathrm{~mm}$; (e), (f) with $\mathrm{t}=28 \mathrm{~mm}$. 


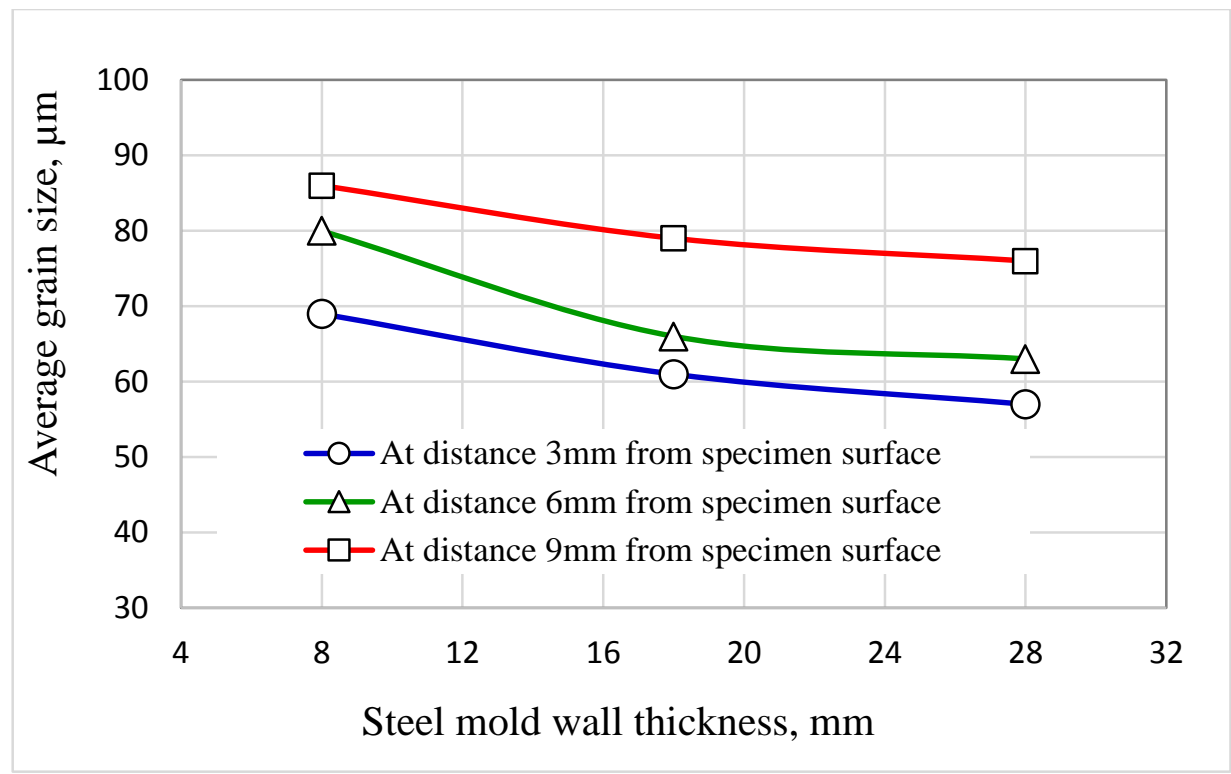

Fig. 11: Average grain size of the AlSiMgMn alloy versus steel mold wall thickness at different distances from specimen surface.

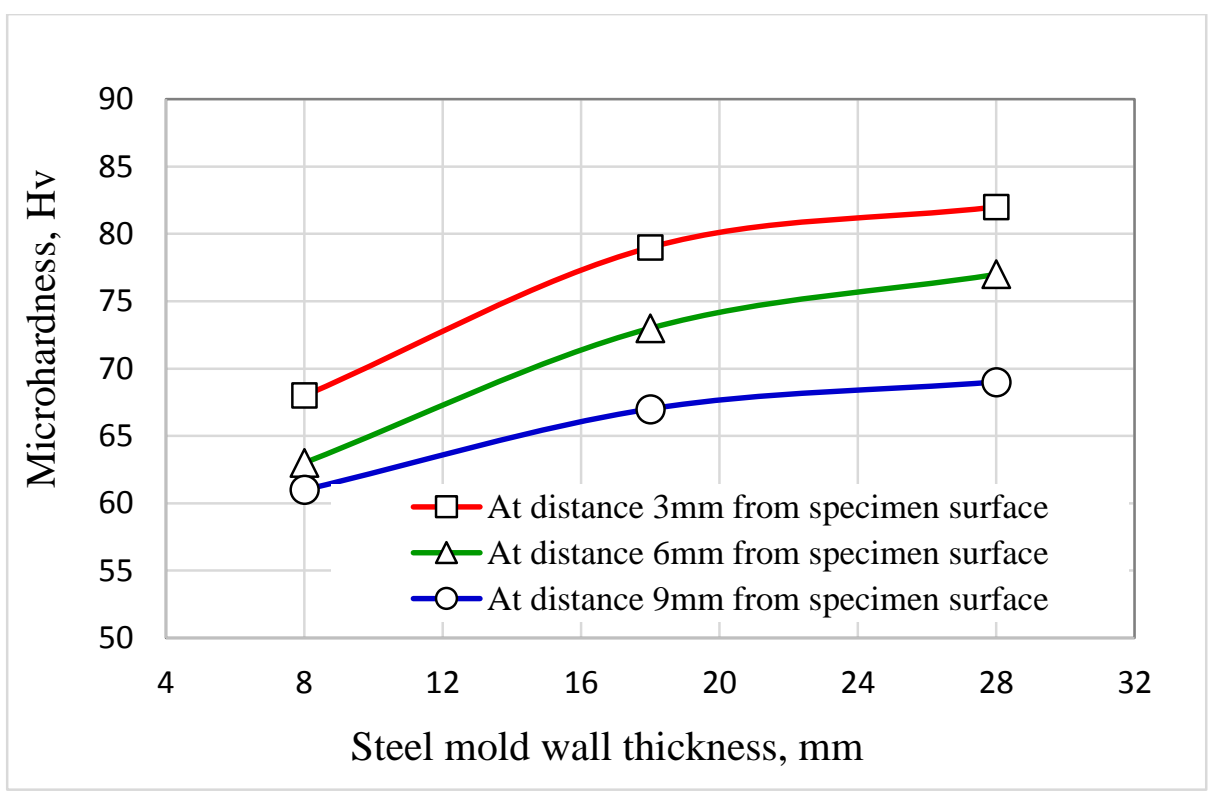

Fig. 12: Vickers microhardness values for the AlSiMgMn alloy versus steel mold wall thickness.

\section{CONCLUSIONS}

The influence of Al-5Ti master alloy with different percentages and mold wall thicknesses on the microstructure and mechanical properties of AlSiMgMn alloy were considered in the current study. The main conclusions may be drawn from the current study are:

- The AlSiMgMn alloy with different percentages of grain refiner Al-5Ti with different percentages is successfully fabricated by die-casting method.

- Hardness of the AlSiMgMn alloy improved with increasing wt.\% Al-5Ti master alloy, the higher hardness value was recorded for the AlSiMgMn alloy with 2 wt.\% of Al-5Ti. This is attributed to the presence of finer grains of $\alpha-\mathrm{Al}$ in the microstructure as a result of $\mathrm{Al}-5 \mathrm{Ti}$ additions.

- The mechanical properties of the AlSiMgMn alloy has been obviously improved by the addition of the Al-5Ti master alloy. With the increasing of Al-5Ti addition from $0 \%$ to $2 \%$ wt. $\%$, the UTS improved from 165 to $208 \mathrm{MPa}$ and the yield strength was increased from 125 to $160 \mathrm{MPa}$, respectively.

- The mold wall thickness affects the rate of solidification of molten metal during mold casting process. As the mold wall thickness increases the solidification rate also 
increases and the grains become lower in size.

- Rapid solidification rate shows fine-grain structure and better mechanical properties, while coarse-grain structure was absorved for slow solidification rate. Hence, the microhardness increased with the increasing of mold wall thickness.

\section{ACKNOWLEDGMENT}

The author would like to express their sincere appreciation to Associated prof. Dalia Saber for her help during this research.

\section{REFERNCES}

[1] Suresh Raj Jain, Dr. Y.Vijayakumar, Dr. S. Vidya Shankar, "Importance of Grain Refinement and Modification of Aluminium Alloys: A Review", International Journal of Science and Research (IJSR), Volume 3 Issue 6, June 2014.

[2] Birol Y. AlB3 master alloy to grain refine AlSi10Mg and AlSi12Cu aluminium foundry alloys. J Alloys Compd 2012;513:150-3.

[3] Kh. Abd El-Aziz, D.Saber, and H.E.M. Sallam, "Wear and Corrosion Behavior of $\mathrm{Al}-\mathrm{Si}$ matrix composite reinforced with Alumina", Springerlink, Journal of Bioand Tribo-Corrosion, 1:5 (2015).

[4] Ren-Guo Guan and Di Tie, "A Review on Grain Refinement of Aluminum Alloys: Progresses, Challenges and Prospects", Acta Metall. Sin. (Engl. Lett.), 2017, 30(5), 409-432.

[5] M. El-Shennawy, Kh. Abdel-Aziz and A. A. Omar Metallurgical and Mechanical Properties of Heat Treatable Aluminum Alloy AA6082 Welds, International Journal of Applied Engineering Research,12;14: pp. 4675-4686 (2017).

[6] D. Saber, R. Abdel-Karim, and A. A. Kandel, Kh. Abd El-Aziz, "Corrosive Wear of Alumina Particles Reinforced Al-Si Alloy Composites" Physics of Metals and Metallography, 2020, Vol. 121, No. 2, pp. 197-203.

[7] Easton MA, Stjohn DH. A model of grain refinement incorporating alloy constitution and potency of heterogeneous nucleant particles. Acta Mater2001;49:1867-78.

[8] Han YF, Li K, Wang J, Shu D, Sun BD. Influence of high-intensity ultrasound on grain refining performance of Al-5Ti-1B master alloy on aluminium. Mater Sci. Eng A 2005;405:306-12.

[9] Easton MA, Stjohn DH. A model of grain refinement incorporating alloy constitution and potency of heterogeneous nucleant particles. Acta Mater2001;49:1867-78.

[10] F. Wang, Z. Liu, D. Qiu, J.A. Taylor, M.A. Easton, M.X. Zhang, "Revisiting the role of peritectics in grain refinement of Al alloys",Acta Mater. 61(1), 360 (2013).
[11] F. Wang, D. Qiu, Z.L. Liu, J.A. Taylor, M.A. Easton, M.X. Zhang, "The grain refinement mechanism of cast aluminium by zirconium" Acta Mater. 61(15), 5636 (2013).

[12] J.J. Ning, X.Q. Li, R.P. Jiang, M.Z. Huang, J. Cent, South Univ. 46(8), 2837 (2015).

[13] B.S. Murty, S.A. Kori, M. Chakraborty, Grain refinement of aluminium and its alloys by heterogeneous nucleation and alloying", International Materials Reviews, 47(1), 3 (2002).

[14] Yu Zhang, Feng Yan, Yu-hong Zhao, Chun-li Song and Hua Hou, "Effect of $\mathrm{Ti}$ on microstructure and mechanical properties of die-cast Al-Mg-Zn-Si alloy", Materials Research Express 7 (2020) 036526.

[15] Wanwu Ding, Tiandong Xia, and Wenjun Zhao, "Performance Comparison of Al-Ti Master Alloys with Different Microstructures in Grain Refinement of Commercial Purity Aluminum", Materials 2014, 7, 3663-3676; doi:10.3390/ma7053663.

[16] K.-J. Kim, H.-J. Kim and C.-Y. Jeong, "Mechanical and die soldering properties of $\mathrm{Al}-\mathrm{Si}-\mathrm{Mg}-\mathrm{Mn}$ cast alloy", Material Research Innovations · May 2014.

[17] Madhusudhan, Narendranaath S., Kumar G. C. M., Mukunda P. G., Experimental study on rate of solidification of centrifugal casting, International Journal of Mechanical and Materials Engineering, 2010, 5(1), p. 101-105.

[18] Madhusudhan, Narendranaath S., Mohankumar G. C., Mukunda P. G., Effect of mold wall on rate of solidification of centrifugal casting, International Journal of Engineering Science and Technology, 2010, 2(11), p. 6092-6096.

[19] Madhusudhan, Narendxranath S., Mohankumar G. C., Effect of Mold wall temperature on rate of solidification of centrifugal casting, International Journal of Advanced Materials Science, 2013, 4(1), p. 37-42.

[20] Katsina Christopher BALA, Reyazul Haque KHAN, "Rate of solidification of aluminium casting in varying wall thickness of cylindrical metallic molds", Leonardo Journal of Sciences, Issue 25, July-December, 2014, pp. 19-30.

[21] Kh. Abd El-Aziz, A. A. Abo El-Nasr, A. Elfasakhany, D. Saber, and M. Helal, "Influence of casting mold wall thickness on the properties and microstructure of A356 alloy reinforced with micro/nanoalumina particles", ARCTIC J. 71, 26-39 (2018).

[22] Cibula A. Discussion of the mechanisms of grain refinementin dilute aluminium alloys. Metall Trans 1972;3:751-3.

[23] Easton MA, Stjohn DH. Grain refinement of aluminum alloys:Part I. the nucleant and solute paradigms-a review of theliterature. Metall Mater Trans A 1999;30 34:1613-23. 
[24] Emamy M, Daman AR, Taghiabadi R, Mahmudi M. Effects of Zr, Ti and B on structure and tensile properties of Al-10Mgalloy (A350). Int J Cast Metals Res 2004;17:1-17.

[25] Kumar GSV, Murthy BS, Chakraborty M. Development of $\mathrm{Al}-\mathrm{Ti}-\mathrm{C}$ grain refiner and study of their grain refining efficiency on $\mathrm{Al}$ and $\mathrm{Al}-7 \mathrm{Si}$ alloy. J Alloys Compds2005;396:143-50.

[26] Madhusudhan, Narendranaath S, Mohankumar G C,and Mukunda P G, "Effect of mould wall thickness on rate of solidification of centrifugal casting", International Journal of Engineering Science and Technology, vol. 2(11), (2010), pp.: 6092-6096.

[27] Katsina Christopher Bala, Reyazul Haque Khan, "Rate of solidification of aluminium casting in varying wall thickness of cylindrical metallic moulds", Leonardo Journal of Sciences, Issue 25, July-December, (2014), pp.:19-30.

[28] Madhusudhan1, Narendranaath S2, Mohankumar G C 2, Mukunda P G, "Effect Of Mold Wall Thickness on Rate of Solidification of Centrifugal Casting", International Journal of Engineering Science and Technology, Vol. 2(11), 2010, 6092-6096

[29] H. R. Sergio, E. Rafael, R. Goytia and K. D. Dheerendra: 'On influence of $\mathrm{Ti}$ and $\mathrm{Sr}$ on microstructure, mechanical properties and quality index of cast eutectic Al-Si-Mg alloy', Mater. Des., 2011, 32, 1865-1871.

[30] 22-Suk Bong Kang, Jing Zhang, Shouren Wang, Jaehyung Cho1, V. U. Stetsenko, "Effect of Cooling Rate on Microstructure and Mechanical Properties in AlSi Alloys", The Japan Institute of Light Metals (2010), pp. 675-680. 